\title{
Awareness on Social Anxiety Disorder Among College Students - A Survey
}

\author{
V.Sharon Keziah', R.Gayathri² and Vishnu Priya.V³ \\ ${ }^{1}$ Undergraduate student Saveetha Dental College and Hospitals, Saveetha Institute of \\ Medical and Technical Sciences, Saveetha University, Chennai,India. \\ ${ }^{2}$ Associate Professor, Department of Biochemistry, Saveetha Dental college and Hospitals, Saveetha \\ institute of Medical and Technical Sciences, Saveetha University, Chennai, India. \\ ${ }^{3}$ Professor Department of Biochemistry, Saveetha Dental College and Hospitals, Saveetha \\ Institute of Medical and Technical Sciences, Saveetha University, Chennai,India.
}

\section{ABSTRACT}

Mental illness is an often ignored risk factor in many of the daily life situations. There are many types of mental illness such as depression, anxiety, bipolar disorder, OCD etc. Among these a type of anxiety known as social anxiety is common especially among young adults. Most of it goes undiagnosed and eventually leads to severe complications in the future such as destructive thoughts and self harm and potentially leading to death. It is a questionnaire based online survey. There were 100 participants in which all of them were college going students .12 questions were asked based on social anxiety disorder.The results were obtained and statistically analysed through SPSS software, chi square test was done to check the association and a p value of 0.05 was said to be statistically significant. This survey has helped $58 \%$ of the students to realize that they might be suffering from social anxiety. From the survey, it was evident that there were many students who were experiencing mild to moderate symptoms but they were unaware of the disorder.Thus, the survey has created an awareness on social anxiety syndrome among college students. There are over 1 million people suffering from social anxiety every year and there should be still many more that are left undiagnosed. Many might be experiencing symptoms like panic attacks even in simple situations so it is important to create awareness about social anxiety disorder in order to help these people to improve their mental health and lead a better life.

KEY WORDS: DEPRESSION, DISORDER,MENTAL HEALTH, PANIC, SOCIAL ANXIETY.

\section{INTRODUCTION}

According to WHO, Health can be defined as a state of physical, mental and social well-being in which diseases are absent. However people often overlook the importance of

\section{ARTICLE INFORMATION}

*Corresponding Author: gayathri.sdc@saveetha.com Received 28th July 2020 Accepted after revision 30th Sep 2020 Print ISSN: 0974-6455 Online ISSN: 2321-4007 CODEN: BBRCBA

Thomson Reuters ISI Web of Science Clarivate Analytics USA and Crossref Indexed Journal

\section{Clarivate
Analytics}

NAAS Journal Score 2020 (4.31) SJIF: 2020 (7.728)

A Society of Science and Nature Publication,

Bhopal India 2020. All rights reserved.

Online Contents Available at: http//www.bbrc.in/

Doi: http://dx.doi.org/10.21786/bbrc/13.8/189 mental health especially in the new millennial(Menninger et al., 1959),(Kendler, 2014). All these can be considered as a mutual triad where the absence of any one of these health can result in affecting the whole well-being. Therefore mental health is as important as physical health and being able to identify one's state of mental health should be fundamental. Epidemiological surveys revealed variable results in the western and european populations probably due to differences in the techniques used to ascertain the diagnosis, however it is clear that social anxiety disorder is one of the most common mental illnesses with a prevalence of 32\%(Kessler et al., 2005). Although both the gender seek treatment for mental illness equally, community surveys indicate that women are somewhat more likely to have the condition(Kessler 
et al., 2005). Population rates of social anxiety disorder in children have been conducted in several countries with an average of $11.1 \%$ higher in males(Kessler et al., 2005; New Zealand. Office of the Prime Minister's Science Advisory Committee, 2011).

There are various mental illnesses such as (Leonard, 2000) (Frazer and Murphy, 1999)depression, (Schou, 1979; Belmaker, 2004) bipolar disorder and social anxiety disorder(Kaye et al., 2004) (Menninger et al., 1959) (Kendall and Hedtke, 2006). Anyone can suffer from mental or emotional health problems, social anxiety disorder being one of the many. Many people experience it at least one time in their lifetime and almost one in five will suffer from a diagnosable social anxiety disorder. Yet despite how common social anxiety disorder is many people make no efforts to improve their own or other's situation. Previous studies on social anxiety disorder and its existing period has reported an average of 19 years, where the disorders could range from panic disorder without agoraphobia, panic disorder, PTSD and OCD(Bruce et al., 2005; Kessler et al., 2005; New Zealand. Office of the Prime Minister's Science Advisory Committee, 2011) . Comparing adult and child surveys together, it is noted that a significant number of people who develop social anxiety disorder in adolescence may recover before reaching adulthood(Pine et al., 1998).

As to the reason why there is no effort being made, it can be considered there is poor knowledge of the consequence or even the presence of such a problem. We often ignore the warnings and red flags or (LeDoux, 2000)(Goddard et al., 2010)emotional messages that tell us or others something is wrong and try to shrug it off. There are some who try to distract themselves from the actual problem with even dangerous things like drugs, alcohol or self-destructive behavior(Malenfant, 2003) (Blachly, 1969). All the frustration, anger, sadness are bottled up hoping that the situation will resolve on its own leading to giving up, and sometimes eventually their lives too.

Social anxiety disorder is a common type and can exist in simple life situations like meeting new people, job interviews, stage fear, eating publicly or in even extreme cases even drinking water can cause social anxiety(Grilo, Masheb and Terence Wilson, 2001)(Wilson et al., 2007). There is fear of being judged(American Psychiatric Association, 2000)(Baker et al., 2002),humiliated and rejected(Cooksey, 1996)(Bryant, Fieldhouse and Bannigan, 2014). No one knows what causes them but having apt knowledge and educating and creating awareness to other especially the youth can be helpful in minimizing the problem worldwide and helping the person individually(Hofmann and DiBartolo, 2014).

\section{MATERIAL AND METHODS}

Study Design: A survey was conducted among 100 college students from various universities, to evaluate their knowledge and awareness on social distress, factors causing and its cure. The participants did the survey voluntarily. Ethical approval and informed consent from the participants were obtained. The study was conducted in the month of may, 2020.

Survey Instrument: The survey instrument which was a questionnaire was prepared after extensive review of the existing literature. The questionnaire was reviewed and amendments were made to improve clarity of the questions to eliminate ambiguous responses. The questionnaire consisted a total of 12 questions. The questionnaire was shared to the participants using online survey platform.

Data Analysis: Only completed surveys were taken for analysis and the incomplete ones were eliminated. The statistical test used is descriptive statistics. All the responses obtained were tabulated and reliability of the data was checked. The statistics done using SPSS software, chi square test was done to check the association and a p value of 0.05 was said to be statistically significant.

Figure 1: Bar graph showing the distribution of participants based on their response about self consciousness. $\mathrm{X}$ axis represents the question "Are you self conscious while eating / drinking /being observed?" and the Y axis represents the percentage of response .64\% of them feel conscious while eating or drinking and 36\% were not conscious.

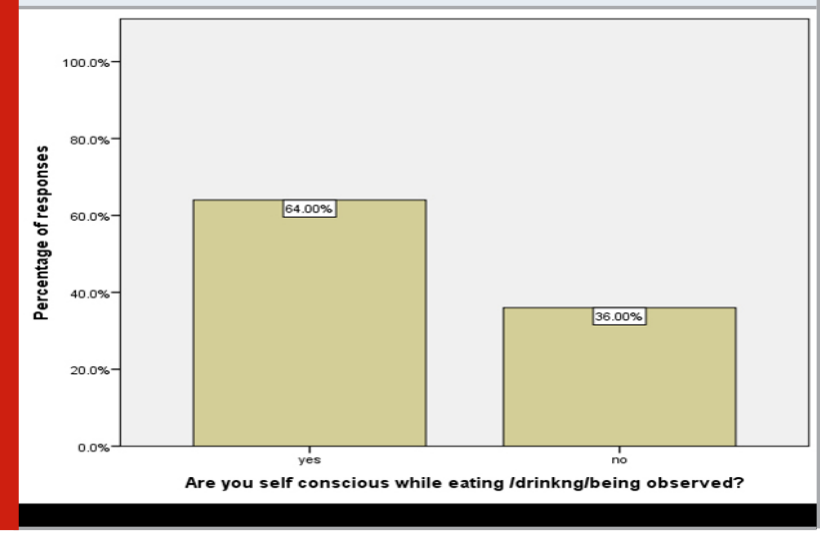

RESULTS AND DISCUSSION

From the survey, When asked if they were self conscious while eating or drinking or being observed $64 \%$ of the participants said yes (figure 1). About 27\% try to avoid meeting new people and $42 \%$ of the participants accepted that they avoid new people sometimes(figure 2). 53\% were afraid of being judged by others(figure 3).About $23 \%$ felt nauseous or sick at social events and 20\% at times felt nauseous however the majority of the study population does not feel any of these symptoms.Majority of the students(60\%) have agreed that they do not have any problem having eye contact while conversing with people.(figure 7).

$28 \%$ of the study participants tremble or sweat when somebody even looks at them.53\% of them have accepted that they were the ones who usually start the conversation(figure 8) and more than 53\% avoid going 
to public gatherings. Surprisingly, $55 \%$ have openly discussed their insecurities to their close friends and family and $19 \%$ sometimes discuss it with their friends and family(figure 10). Almost 73\% have felt lonely or sad when surrounded by people. There were a total of 64 students who were self conscious while eating or drinking or being observed. This shows that people can be affected even in simple lifestyle events and habits like eating. It could be fear or embarrassment of eating in a certain way that could be viewed as inappropriate for the individual. According to Takuya, it can also be correlated with shape and weight concerns especially for young girls.

Figure 2: Bar graph showing the percentage distribution of responses from the participants based on their opinion to meet new people. $\mathrm{X}$ axis represents the question "Do you avoid meeting new people?" and the $\mathrm{Y}$ axis represents the percentage of response $.27 \%$ of the participants avoid meeting new people, $31 \%$ denied it and a majority of $42 \%$ avoid meeting new people at times.

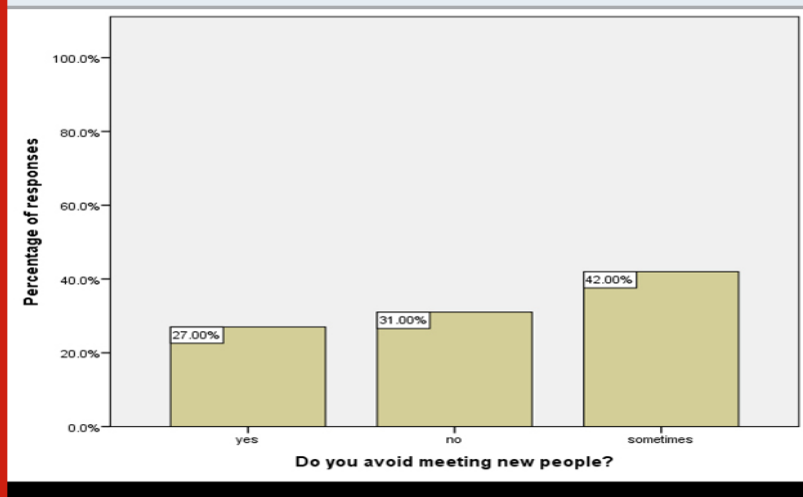

Figure 3: Bar graph showing the percentage distribution of responses from the participants about being judged by other people. $\mathrm{X}$ axis represents the question "Are you afraid of being judged by others?" and the $\mathrm{Y}$ axis represents the percentage of response . 53\% of them felt afraid of being judged by others.

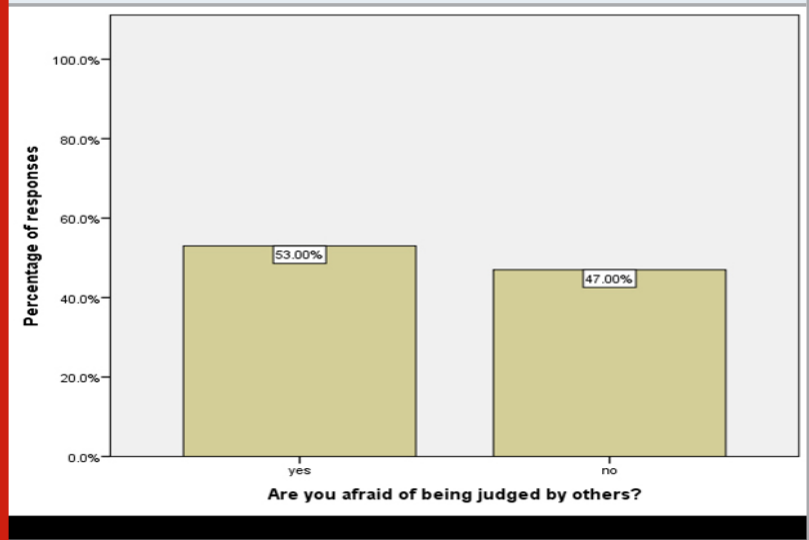

Many students were having trouble conversing with new people or avoiding meeting new people or public gatherings. While sometimes it may be due to simple
Figure 4: Bar graph showing the percentage distribution of responses from the participants about feeling lonely or sad . X axis represents the question "Have you ever felt lonely or sad even when surrounded by people?" and the $\mathrm{Y}$ axis represents the percentage of response $.43 \%$ of them felt lonely or sad.

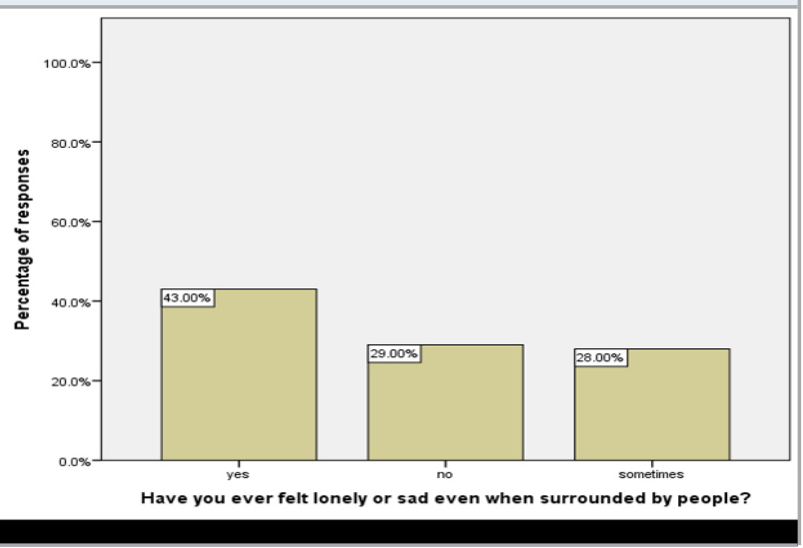

Figure 5: Bar graph depicts the association between Gender and participants who feel that they might suffer from social anxiety .X axis represents the question 'Do you think you are suffering from social anxiety' and Y axis represents the percentage of participants. Blue color denotes males and green color denotes females. Majority of (41\%) female participants felt that they were possibly suffering from social anxiety more than males.Pearson chi square test was done and $p$ value $=0.0012(p<0.005)$, statistically significant.

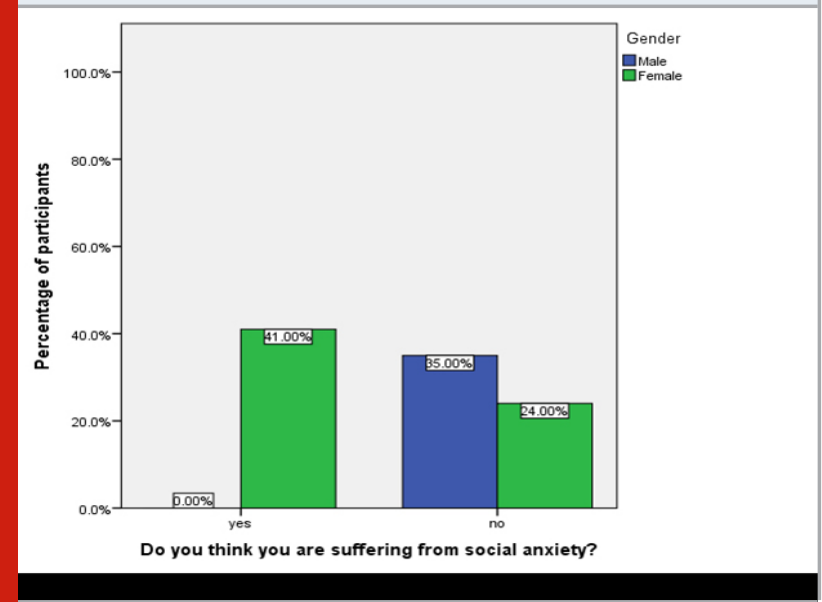

reasons like just considering it a time waste sometimes people have felt pressured to answer questions about personal lives or any unwanted conversation. Some people just prefer to stay at home and not socialize. Sometimes the fear of public speaking can cause brain freeze in certain individuals. They could start sweating or feel nauseous indicating a severe type of social phobia. More than 73 students feel embarrassed when passing a comment on them and 53 of them are afraid of being judged. While it is absolutely normal to feel like this when they are in a competition or somewhere where judging is a part of it,which is not a concern. However 
feeling sick even when at a simple comment could be an indication of social anxiety. Some even sweat and tremble when someone looks at them, they could be having a panic attack. Some have even felt lonely even when surrounded by others. At this point they already have a feeling of isolation even though they are actually not.

Figure 6: Bar graph depicts the association between Gender and the opinion of participants who felt embarrassed when someone passed a comment on them .X axis represents the question 'Will you feel embarrassed when someone passes a comment on you?' and Y axis represents the participant's opinion for the same. (Blue) denotes males and (green) denotes females. Majority of (46\%) female participants felt embarrassed when someone passed a comment on them than the male participants.. Pearson chi square test was done and $p$ value $=0.034(p<0.005)$, statistically significant.

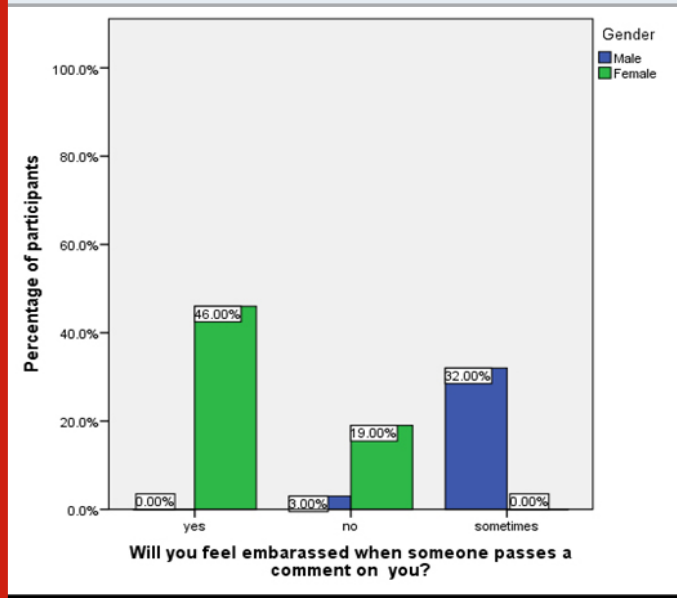

Figure 7: Bar graph showing the distribution of participants based on their response about the opinion of having eye contact while conversing. $\mathrm{X}$ axis represents the question "Do you make a little/no eye contact while conversing with people?" and the $\mathrm{Y}$ axis represents the percentage of respons.60\% of the participants do not have any problem having eye contact while conversing with people.

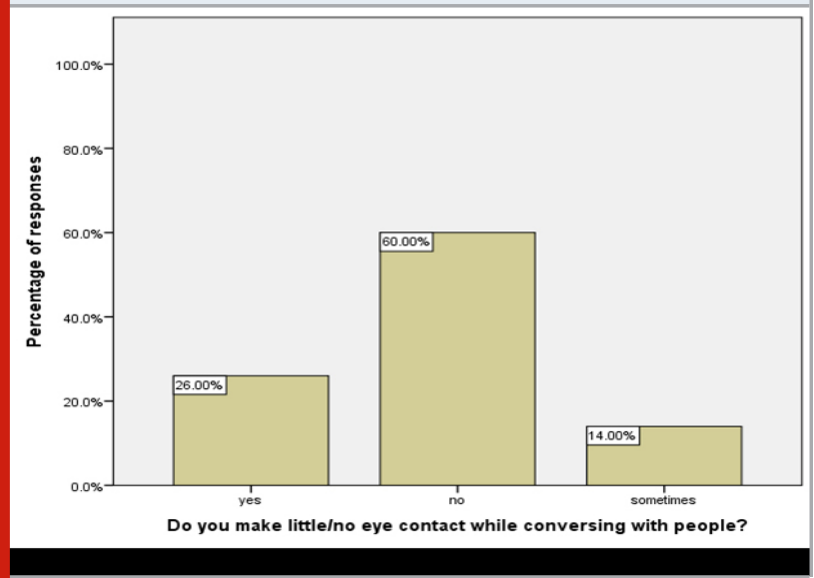

Figure 8: Bar graph showing the distribution of participants based on their response on having experienced symptoms like trembling or sweating when somebody even looks at them. $\mathrm{X}$ axis represents the question "Do you tremble or sweat when somebody looks at you?" and the $Y$ axis represents the percentage of response . $72 \%$ of the participants experienced trembling or sweating when somebody even looked at them.

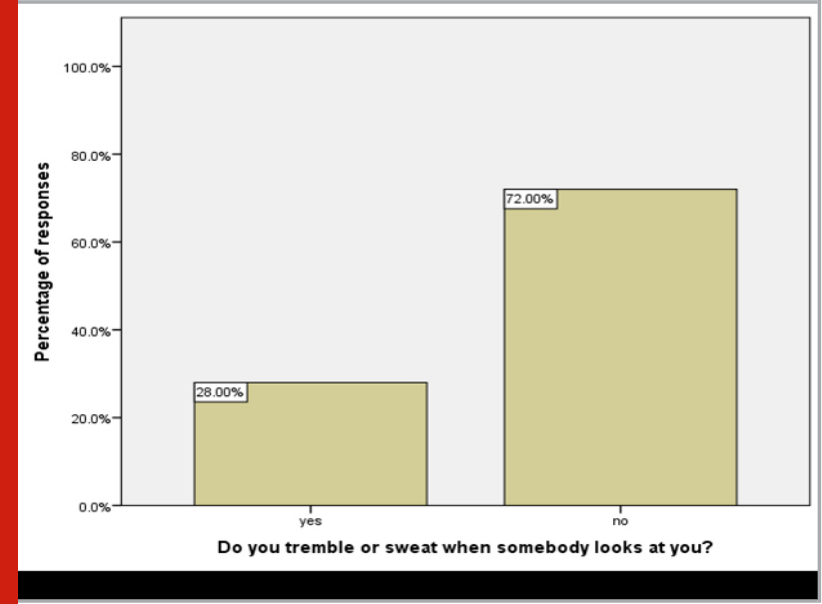

Figure 9: Bar graph showing the distribution of participants based on their response to avoid public gatherings. $\mathrm{X}$ axis represents the question "Do you avoid going to public gatherings ?" and the $\mathrm{Y}$ axis represents the percentage of response. $27 \%$ of the participants avoided public gathering.

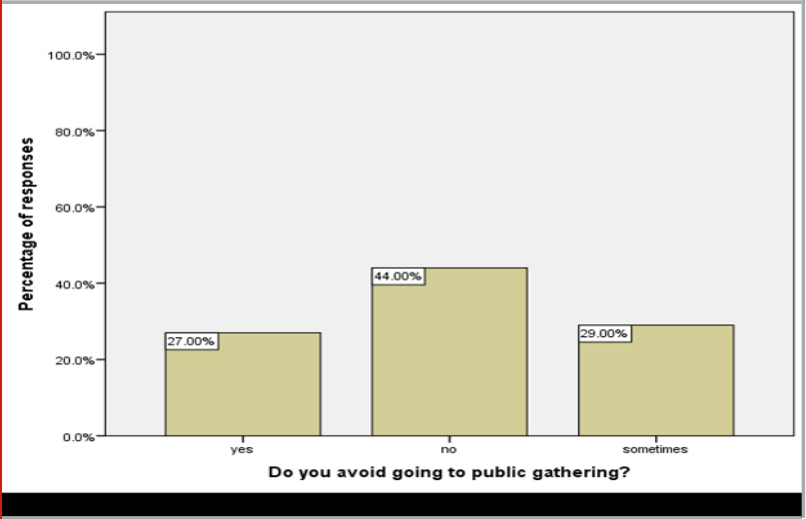

Around 58 students have realized they might be suffering from social anxiety. This shows that there is no awareness about mental health and its ill effects. Parents and teachers play a pivotal role in shaping students' lives mentally as well. They should be able to recognize the signs and not be afraid to give the child treatment that could be lifesaving in certain situations. There are many ways to help people who are suffering like cognitive therapy, talking in groups and certain medications. There are many call guidelines all over the world where people listen to their problems. 
Figure 10: Bar graph showing the distribution of participants based on their response about discussing their insecurities to their close friends and family. $\mathrm{X}$ axis represents the question "Have you openly discussed your insecurities?" and the Y axis represents the percentage of response. Many of the students (55\%) have agreed to openly discuss insecurities and inferiority to their loved ones.

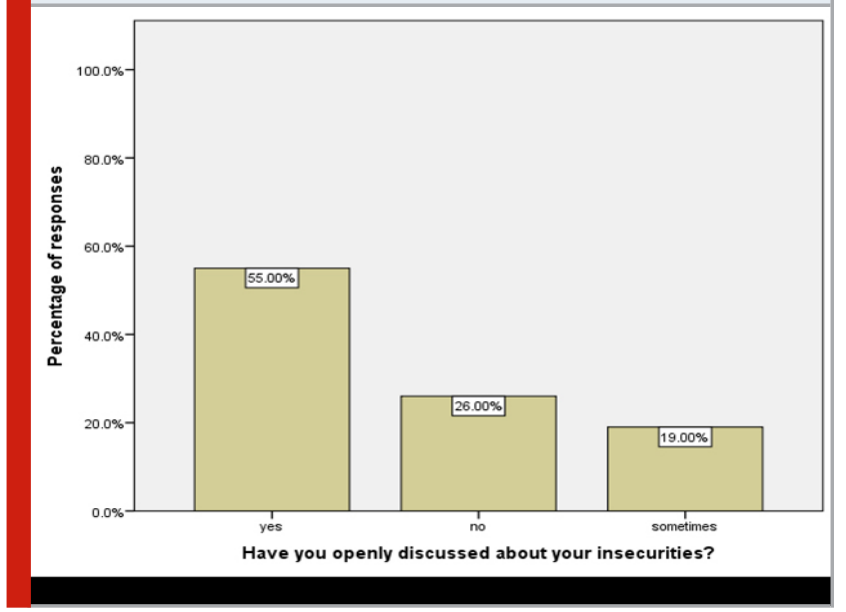

\section{CONCLUSION}

Social anxiety is the third most common mental disorder especially affecting young adults. Often many fail to diagnose mistaking it as part of growth spurt. In some cases it could potentially lead to individuals having self harms and suicidal thoughts. Many might be experiencing symptoms like panic attacks even in simple situations.From the survey it was very much evident that the majority of women exhibited the symptoms of social distress than the male participants. This survey has created an awareness about social anxiety disorder in order to help people improve their mental health and lead a better life.

\section{ACKNOWLEDGEMENTS}

The authors would like to acknowledge the help and support rendered by the Department of Biochemistry and the Management of Saveetha Dental College and Hospitals for their constant assistance with the research.

Conflict of Interest: There is no conflict of interest.

\section{REFERENCES}

American Psychiatric Association (2000) Diagnostic and Statistical Manual of Mental Disorders, 4th Edition, Text Revision (DSM-IV-TR). American Psychiatric Association.

Baker, S. L. et al. (2002) 'The liebowitz social anxiety scale as a self-report instrument: a preliminary psychometric analysis', Behaviour research and therapy, 40(6), pp. 701-715.
Belmaker, R. H. (2004) 'Bipolar Disorder', New England Journal of Medicine, pp. 476-486. doi: 10.1056/ nejmra035354.

Blachly, P. H. (1969) 'PREVENTION OF SUICIDE WORLD HEALTH ORGANIZATION, GENEVA', American Journal of Public Health and the Nations Health, pp. 1267-1268. doi: 10.2105/ajph.59.7.1267-b.

Bruce, S. E. et al. (2005) 'Influence of Psychiatric Comorbidity on Recovery and Recurrence in Generalized Anxiety Disorder, Social Phobia, and Panic Disorder: A 12-Year Prospective Study', American Journal of Psychiatry, pp. 1179-1187. doi: 10.1176/appi. ajp.162.6.1179.

Bryant, W., Fieldhouse, J. and Bannigan, K. (2014) Creek's 0ccupational Therapy and Mental Health E-Book. Elsevier Health Sciences.

Cooksey, R. W. (1996) Judgment Analysis: Theory, Methods, and Applications. Emerald Group Publishing.

Frazer, A. and Murphy, A. L. (1999) 'MECHANISMS OF ACTIONS OF ANTIDEPRESSANTS', The American Journal of Geriatric Psychiatry, p. 9. doi: 10.1097/00019442199911001-00027.

Goddard, A. W. et al. (2010) 'Current perspectives of the roles of the central norepinephrine system in anxiety and depression', Depression and Anxiety, pp. 339-350. doi: 10.1002/da.20642.

Grilo, C. M., Masheb, R. M. and Terence Wilson, G. (2001) 'Subtyping binge eating disorder', Journal of Consulting and Clinical Psychology, pp. 1066-1072. doi: 10.1037/0022-006x.69.6.1066.

Hofmann, S. G. and DiBartolo, P. M. (2014) Social Anxiety: Clinical, Developmental, and Social Perspectives. Elsevier.

Kaye, W. H. et al. (2004) 'Comorbidity of Anxiety Disorders With Anorexia and Bulimia Nervosa', American Journal of Psychiatry, pp. 2215-2221. doi: 10.1176/appi.ajp.161.12.2215.

Kendall, P. C. and Hedtke, K. A. (2006) Cognitivebehavioral Therapy for Anxious Children: Therapist Manual. Workbook Pub Incorporated.

Kendler, K. S. (2014) 'The Structure of Psychiatric Science', American Journal of Psychiatry, pp. 931-938. doi: 10.1176/appi.ajp.2014.13111539.

Kessler, R. C. et al. (2005) 'Lifetime Prevalence and Age-of-Onset Distributions of DSM-IV Disorders in the National Comorbidity Survey Replication', Archives of General Psychiatry, p. 593. doi: 10.1001/ archpsyc.62.6.593.

LeDoux, J. E. (2000) 'Emotion Circuits in the Brain', Annual Review of Neuroscience, pp. 155-184. doi: 10.1146/annurev.neuro.23.1.155.

Leonard, B. E. (2000) 'Peripheral markers of depression', 
Current Opinion in Psychiatry, pp. 61-68. doi: 10.1097/00001504-200001000-00011.

Malenfant, É. C. (2003) ‘Massimo Borlandi et Mohamed Cherkaoui (dir.), Le suicide un siècle après Durkheim. Paris, Presses Universitaires de France, 2000, 260 p., réf., index', Anthropologie et Sociétés, p. 232. doi: 10.7202/007024ar.

Menninger, K. et al. (1959) 'The unitary concept of mental illness', Pastoral Psychology, pp. 13-19. doi: 10.1007/bf01741038.

New Zealand. Office of the Prime Minister's Science Advisory Committee (2011) Improving the Transition:
Reducing Social and Psychological Morbidity During Adolescence.

Pine, D. S. et al. (1998) 'The Risk for Early-Adulthood Anxiety and Depressive Disorders in Adolescents With Anxiety and Depressive Disorders', Archives of General Psychiatry, p. 56. doi: 10.1001/archpsyc.55.1.56.

Schou, M. (1979) 'Lithium in the Treatment of Other Psychiatric and Nonpsychiatric Disorders', Archives of General Psychiatry, p. 856. doi: 10.1001/ archpsyc.1979.01780080030009.

Wilson, G. T. et al. (2007) 'Psychological treatment of eating disorders', American Psychologist, pp. 199-216. doi: 10.1037/0003-066x.62.3.199. 